\title{
Evidence-Based Mental Health
}

With this Issue, Evidence-Based Mental Health (EBMH) celebrates 5 years of publication. This proves wrong those sceptics who thought that there was insufficient high quality evidence in the field of mental health to make a quarterly current awareness journal, such as $E B M H$, viable. Over time, the number of articles that meet our stringent selection criteria seems to be increasing.

From the next issue (February 2003), there will be a number of changes in the way that $E B M H$ is produced. During the last 5 years, the main editorial activity (including selection of articles, preparation of abstracts, and the coordination of the production of the journal) has taken place at the Health Information Research Unit at McMaster University in Ontario, Canada. We are enormously grateful to Brian Haynes and his team at McMaster (listed on the inside cover) for sharing their expertise and helping us to develop the journal since its inception. This editorial role will now be taken over by Bazian Ltd: a UK organ- isation, with a strong track record in the field of evidence-based health care, who already perform a similar function for other journals and evidence-based products, including Evidence-Based Cardiovascular Medicine (published by Elsevier Science) and Clinical Evidence (published by the BMJ Publishing Group).

The purpose and procedures and the editors of $E B M H$ will remain the same and we anticipate that there should be very little change to the journal itself - although we may make more additional material available on the website. We would like to take this opportunity to thank our readers and subscribers for your support over the last 5 years. As always, we are delighted to receive any feedback or suggestions on how $E B M H$ can be improved.

JOHN GEDDES, MD

SHIRLEY REYNOLDS, PhD

DAVID STREINER, PhD PETER SZATMARI, MD

\section{How to cite Evidence-Based Mental Health}

\section{CITATION OF MATERIAL FROM THE NOTEBOOK:}

- Streiner D, Geddes J. Some useful concepts and terms used in articles about diagnosis [EBMH notebook]. Evidence-Based Mental Health 1998 Feb;1:6-7.

CITATION FOR MATERIAL TAKEN FROM A STRUCTURED ABSTRACT, WRITTEN WITHOUT ATTRIBUTION BY A STAFF MEMBER:

- Caregiver training delayed admission of patients with dementia to nursing homes [abstract]. Evidence-Based Mental Health 1998 Feb;1:9. Abstract of: Brodaty H, Gresham M, Luscombe G. The Prince Henry Hospital dementia caregivers' training programme. Int J Geriatr Psychiatry 1997 Feb;12:183-92.

CITATION FOR MATERIAL TAKEN FROM A COMMENTARY TO AN ARTICLE:

- Bradley C. Commentary on "Purchase of a handgun was associated with an increased risk of suicide or death by homicide." EvidenceBased Mental Health 1998 Feb;1:28. Comment on: Cummings P, Koepsell TD, Grossman DC, et al. The association between the purchase of a handgun and homicide or suicide. Am J Public Health 1997 Jun;87:974-8. 